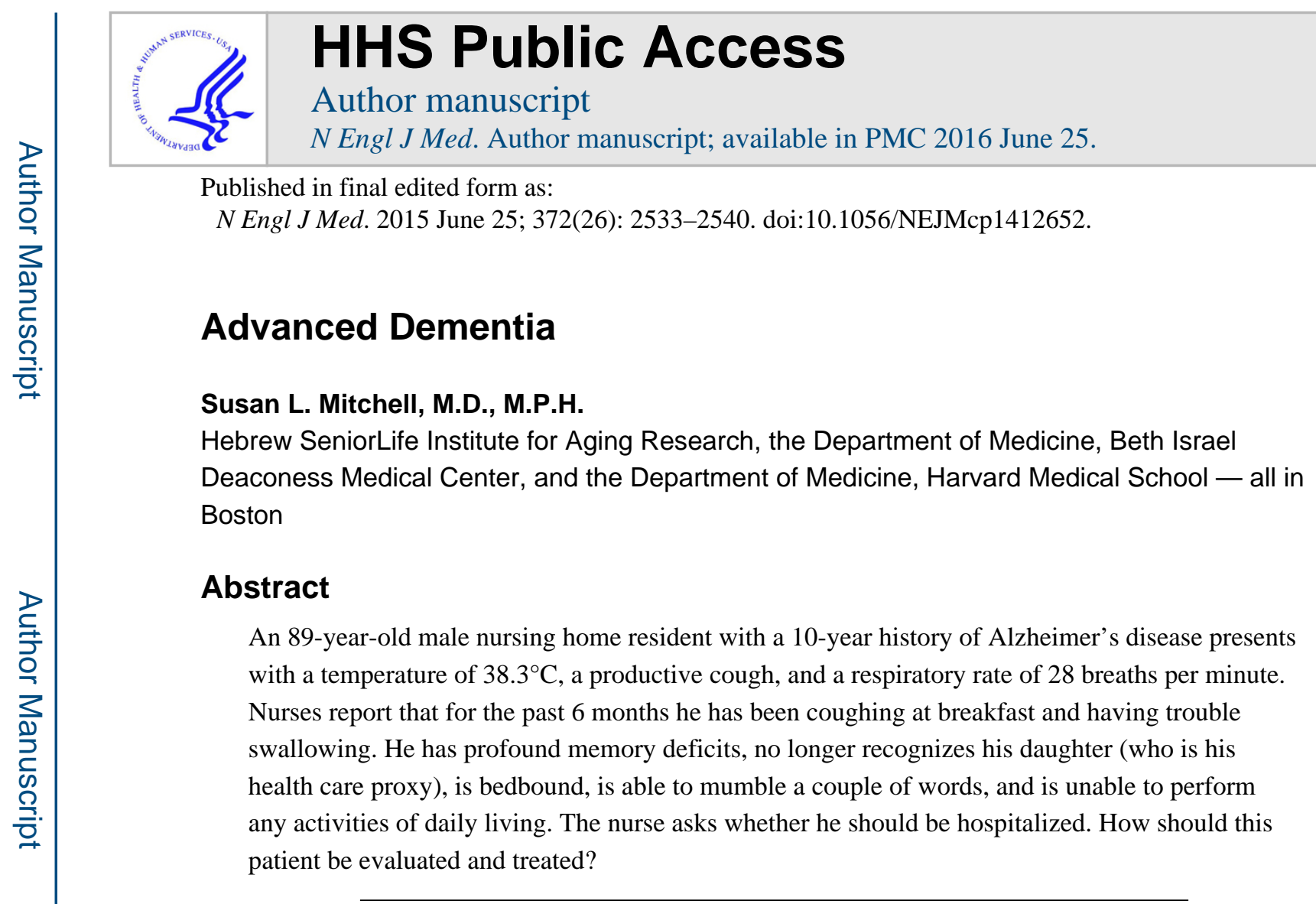

\title{
The Clinical Problem
}

In 2014, Alzheimer's disease affected approximately 5 million persons in the United States, a number that is projected to increase to approximately 14 million by $2050 .{ }^{1}$ In 2011 , it was the sixth leading cause of death in the United States. ${ }^{2}$ Population-based studies estimate that 600,000 Americans with Alzheimer's disease died in $2010 .{ }^{3}$ The median survival after diagnosis ranges from 3 to 12 years, ${ }^{4}$ with patients spending most of that time in the severest stage. ${ }^{5}$ Nursing homes are the most common sites of death ${ }^{5-7}$ and are thus important for terminal care.

Dementia is a progressive, incurable illness. In patients with advanced dementia, the final year of life is characterized by a trajectory of persistently severe disability. ${ }^{8}$ Stage 7 on the Global Deterioration Scale (ranging from 1 to 7, with higher stages indicating worse dementia) provides a useful description of the features of advanced dementia, ${ }^{9}$ including profound memory deficits (e.g., inability to recognize family members), minimal verbal abilities, inability to ambulate independently, inability to perform any activities of daily living, and urinary and fecal incontinence.

The clinical course of advanced dementia was described in the Choices, Attitudes, and Strategies for Care of Advanced Dementia at the End-of-Life (CASCADE) study, which prospectively followed 323 nursing home residents with this condition for 18 months. ${ }^{10}$ The

Address reprint requests to Dr. Mitchell at the Hebrew SeniorLife Institute for Aging Research, 1200 Centre St., Boston, MA 02131, or at smitchell@hsl.harvard.edu.

No potential conflict of interest relevant to this article was reported.

Disclosure forms provided by the author are available with the full text of this article at NEJM.org. 
median survival was 1.3 years. The most common clinical complications were eating problems ( $86 \%$ of patients), febrile episodes (53\% of patients), and pneumonia ( $41 \%$ of patients).

Estimating life expectancy in cases of advanced dementia is difficult. ${ }^{11,12}$ Eligibility guidelines for the Medicare hospice benefit require that patients with dementia have an expected survival of less than 6 months, as assessed by their reaching stage $7 \mathrm{c}$ on the Functional Assessment Staging tool (a scale ranging from stage 1 to stage $7 \mathrm{f}$, with stage $7 \mathrm{f}$ indicating the most severe dementia) and having had one of six specified complications in the past year (Table 1). ${ }^{13}$ However, these eligibility guidelines do not accurately predict survival. ${ }^{11,12}$ An alternative measure - a risk score to predict 6-month survival among patients with advanced dementia - was derived with the use of nationwide Minimum Data Set information (a patient assessment instrument federally mandated in U.S. nursing homes) and then prospectively evaluated in 602 nursing home residents. ${ }^{11}$ The predictive ability of the score for 6-month survival was moderate (area under the receiver-operatingcharacteristic curve $[\mathrm{AUC}], 0.68$ ) but better than that of hospice eligibility guidelines (AUC, 0.55). Given the challenge of predicting life expectancy among patients with advanced dementia, access to palliative care should be determined on the basis of a desire for comfort care, rather than the prognostic estimates.

\section{Strategies and Evidence}

\section{Approach to Decision Making}

Advance care planning is a cornerstone of the care of patients with advanced dementia. Providers should educate health care proxies about the disease trajectory (i.e., the final stage of an incurable disease) and expected clinical complications (e.g., eating problems and infections). Providers should also counsel proxies about the basic tenet of surrogate decision making, ${ }^{14}$ which is to first consider written or oral advance directives previously expressed by patients and then choose treatment options that align with these advance directives (e.g., a do-not-hospitalize order) before acute problems arise, and ideally, avoid treatments that are inconsistent with the patients' wishes. In the absence of clear directives, proxies will have to either exercise substituted judgment according to what they think the patient would want or make a decision based on the patient's best interests. Some observational studies showed that patients with advanced dementia who had advance directives had better palliative care outcomes (e.g., less tube feeding, ${ }^{15,16}$ fewer hospitalizations near the end of life, ${ }^{10,17}$ and greater enrollment in hospice ${ }^{18}$ ) than those without advance directives.

Treatment decisions for patients with advanced dementia should be guided by the goals of care; providers and patients' health care proxies must share in the decision making. After the provider has explained the clinical issue to the health care proxy, framed in the context of advanced dementia, the proxy should then articulate the goal or level of care that aligns with the patient's preferences, such as treatments that promote comfort only, all medical interventions that may prolong life (e.g., mechanical ventilation), or something in between (e.g., administration of antimicrobial agents) that may help the patient return to the preacute-illness baseline status (Table 2). In prospective studies, more than $90 \%$ of proxies stated that the goal of care was comfort. ${ }^{10,21}$ 
Once a goal of care is established, treatment options that best align with that goal should be considered. In the absence of randomized trials comparing the outcomes of treatment options for common clinical problems in patients with advanced dementia, information is derived from observational studies, including analyses of large clinical and administrative data sets and smaller prospective cohort studies.

\section{Clinical Complications}

Eating Problems-Eating problems are the most common complication in advanced dementia. ${ }^{10,19}$ Eating problems include oral dysphagia (e.g., pocketing food in the cheek), pharyngeal dysphagia causing aspiration, the inability to feed oneself, or the refusal to eat. When eating problems are present, acute conditions should be considered (e.g., a dental problem) and reversible issues should be addressed as guided by the goals of care. Oral intake can be encouraged by means of conservative approaches, such as the presentation of smaller meals, altered food textures, and high-calorie supplements. A qualitative synthesis of the literature showed that of these approaches, only high-calorie supplementation was supported by moderate-strength evidence (e.g., evidence from randomized trials) to promote weight gain in patients with dementia; none of the approaches improved function or survival. ${ }^{29}$

Two options for the treatment of sustained eating problems are continued hand feeding and tube feeding. The goal of hand feeding is to provide food to the extent that it is comfortable for the patient, rather than to ensure a prescribed caloric intake. Hand feeding takes time but allows patients to enjoy tasting food and to interact with caregivers during meals. Proxies should be assured that hand feeding instead of tube feeding does not imply that medical care has been stopped, but rather that care is focused on palliation.

Randomized trials are lacking that compare tube feeding with hand feeding in patients with advanced dementia. A 2009 Cochrane review of observational studies concluded that there was insufficient evidence to support the benefits of tube feeding in patients with advanced dementia in terms of survival, quality of life, nutrition, functional status, the prevention of aspiration, or the prevention and healing of pressure ulcers. ${ }^{23}$ Two analyses of Minimum Data Set repositories showed no significant difference in survival between nursing home residents with advanced dementia who had feeding tubes and those who did not have feeding tubes. ${ }^{15,16}$ Another study involving the use of this data set showed a higher incidence of new pressure ulcers and less frequent healing of existing ulcers among patients with advanced dementia who were tube-fed than among those without feeding tubes. ${ }^{24}$

Risks associated with tube feeding include procedural complications from insertion and the use of chemical or physical restraints if an agitated patient tries to remove the tube. Tube blockages and dislodgments are common reasons for visits to the emergency department ${ }^{30}$; such visits are potentially burdensome for frail persons.

Several organizations have published recommendations against tube feeding in patients with advanced dementia ${ }^{25-28}$; such recommendations may be useful as decision-support tools when counseling proxies. A randomized trial involving 256 residents and their proxies in 24 North Carolina nursing homes showed that proxies who were randomly assigned to use a 
decision-making aid (vs. usual care) regarding feeding options for patients with advanced dementia had reduced decisional conflict and increased knowledge about their choice. Most proxies opted for hand feeding; tube feeding was rare in both groups (1 patient in the intervention group and 3 patients in the control group, $\mathrm{P}=0.34){ }^{31}$

Infections-Infections are very common in patients with advanced dementia. ${ }^{10,32,33}$ The Study of Pathogen Resistance and Exposure to Antimicrobials in Dementia (SPREAD), which prospectively followed 362 nursing home residents with advanced dementia, showed that in a 12-month period, two thirds were suspected to have infections, most commonly of the urinary or respiratory tract. ${ }^{21}$ Approximately half of the patients with advanced dementia receive a diagnosis of pneumonia in the last 2 weeks of life. ${ }^{34}$ Six months after a suspected diagnosis of pneumonia in patients with advanced dementia, the rate of death from any cause is $50 \% .^{10,35}$

The use of antimicrobial agents is extensive in patients with advanced dementia. ${ }^{20,21,32,33} \mathrm{In}$ two prospective, multicenter studies, 52 to $66 \%$ of nursing home residents with advanced dementia were prescribed antimicrobials at least once during a 12-month period and $42 \%$ in the last 2 weeks of life. ${ }^{21,33}$ Much of this use may be inappropriate. In SPREAD, 75\% of suspected infections were treated with antimicrobials, ${ }^{21}$ but less than half of all treated infections and only $19 \%$ of treated urinary tract infections met minimal clinical criteria for the initiation of antimicrobials (see the Supplementary Appendix, available with the full text of this article at NEJM.org). ${ }^{36}$ It is well recognized that asymptomatic bacteriuria should not be treated, ${ }^{36}$ but what constitutes symptomatic urinary tract infection in patients who are essentially mute is unclear. Nevertheless, a diagnosis of urinary tract infections is often made - but should not be made - on the basis of vague changes in mental status without objective signs of an infection (e.g., fever).$^{32}$ Urinalyses and urine cultures are frequently positive in patients with advanced dementia, regardless of their clinical status ${ }^{32}$; negative tests may help rule out a urinary tract infection, but positive tests do not necessarily indicate a requirement for treatment.

The misuse of antimicrobials contributes to an unnecessary treatment burden and the emergence of multidrug-resistant organisms, ${ }^{21}$ which is a growing public health threat. In SPREAD, 67\% of nursing home residents were colonized with these organisms, and exposure to antimicrobials was the strongest risk factor for acquisition. ${ }^{21}$

We are unaware of any randomized trials that have examined the effects of antimicrobials on survival or symptom relief in persons with advanced dementia. The extent of discomfort from infections in patients with dementia is unknown; antimicrobials may not provide greater symptom relief than do palliative measures. In the CASCADE study, patients with advanced dementia and pneumonia who were treated with antimicrobials lived an average of 273 days longer but also had more discomfort (i.e., lower scores on the Symptom Management at the End-of-Life in Dementia scale, ${ }^{38}$ as rated by nurses) than those who did not receive antimicrobials. ${ }^{20}$ Rates of death did not differ according to the route of administration (oral, intramuscular, or intravenous). 
These data support the use of caution regarding the initiation of antimicrobials in patients with advanced dementia. Health care proxies should be counseled to expect infections in patients; they should also be educated regarding the risks and benefits associated with various treatments. If comfort is the goal, with a preference to forgo antimicrobials, symptoms should be treated with palliation only. If prolongation of life is the goal, initiation of antimicrobials is reasonable if there are clinical criteria to support it ${ }^{36}$ and if the treatment burden is minimized by using the least invasive route of administration and avoiding hospitalization, if possible.

\section{Hospitalization}

Of persons in the United States who die with dementia, approximately $16 \%$ die in hospitals. ${ }^{6,7}$ Between 2000 and 2007, a total of $19 \%$ of nursing home patients in the United States who died with advanced dementia had a burdensome transition near the end of life (i.e., hospitalization in the last 3 days of life, multiple hospitalizations in the last 90 days of life, or care in multiple nursing homes after hospitalization in the last 90 days of life). ${ }^{17}$ Infections are the most common reason for hospitalization. ${ }^{30}$ An estimated $75 \%$ of hospitalizations may be medically unnecessary or are discordant with the patients' preferences and are thus avoidable. ${ }^{30}$ The goal of care for most patients is comfort, ${ }^{10,21}$ and hospitalization seldom promotes that goal, except in rare cases, such as in the treatment of hip fractures and when palliative care is unavailable. Hospitalization may make sense if prolongation of life remains the goal, although common illnesses such as pneumonia may be treated with similar efficacy outside the hospital. ${ }^{20,22}$ Advance care planning is the key to reducing unwanted and unnecessary hospitalizations. According to observational studies, advance care planning in the form of a do-not-hospitalize order is a key modifiable factor associated with avoiding hospitalization. ${ }^{17,30}$

\section{Palliative and Hospice Care}

Patients with advanced dementia commonly have distressing but potentially treatable symptoms. In observational studies, a quarter to a half of nursing home residents with advanced dementia had documented pain in the last weeks of life, and approximately a third had dyspnea, agitation, or aspiration. ${ }^{10,37}$ Standard palliative care and geriatric management approaches to these problems apply to patients with advanced dementia, with several unique considerations. Pain is difficult to assess in patients with advanced dementia and hence is under-recognized and undertreated. ${ }^{18,37}$ Dementia-specific pain measures based on caregiver assessment have been developed and validated (see the Supplementary Appendix) ${ }^{38,39}$ Agitation in advanced dementia is best managed with nonpharmacologic approaches. Antipsychotic medications are often ineffective ${ }^{40}$; in 2005, a meta-analysis of placebo-controlled trials showed an increased risk of death associated with the use of these drugs in patients with dementia, ${ }^{41}$ and the Food and Drug Administration issued a black-box warning regarding the use of atypical antipsychotic agents in patients with dementia.

When available, palliative care consultation or hospice referral should be offered. Unfortunately, formal palliative care services are lacking in most nursing homes. ${ }^{42}$ Moreover, although hospice enrollment of patients with dementia has increased over the past decade, many barriers to accessing hospice care persist, ${ }^{43}$ particularly the requirement of 
having a life expectancy of less than 6 months. In 2007, only one third of Americans dying with dementia received hospice care, and in 2013, only $16 \%$ of enrollees in hospice had a primary diagnosis of dementia. ${ }^{44}$ Observational studies show that patients with advanced dementia who are enrolled in hospice have a lower risk of dying in the hospital ${ }^{45}$ and of being hospitalized in the last 30 days of life ${ }^{46}$ and a higher frequency of treatment for pain and dyspnea ${ }^{18,47}$; furthermore, their families have greater satisfaction with patient care. ${ }^{18,48}$

\section{Medication Use}

Daily medications should align with the goals of care, and drugs of questionable benefit should be discontinued. In 2008, an expert panel declared that the use of certain medications is inappropriate (i.e., not clinically beneficial) in patients with advanced dementia for whom comfort is the goal. ${ }^{49}$ Cross-sectional analyses of a nationwide pharmacy database showed that $54 \%$ of nursing home residents with advanced dementia were prescribed at least one of those medications. Among the inappropriate medications prescribed, the most common were cholinesterase inhibitors (36\%), memantine (25\%), and statins (22\%). Medications with questionable benefits accounted for $35 \%$ of the mean 90-day medication expenditures for the nursing home residents with advanced dementia to whom they were prescribed. ${ }^{50}$ Clinical trials of the use of cholinesterase inhibitors and memantine in patients with latestage dementia do not involve patients at stage 7 on the Global Deterioration Scale; therefore, there are no compelling data to support the use of these drugs in such patients.

\section{Areas of Uncertainty}

Observational studies of the experiences of patients with advanced dementia have shown that improvements in some aspects of care are needed, including better education of patients and families about end-stage disease, greater engagement of patients and families in advance care planning, provision of care concordant with patient preferences, less use of burdensome interventions of limited benefit (e.g., tube feeding and hospitalization), and better treatment of distressing symptoms. Randomized trials are needed to evaluate practice interventions aimed at improving these outcomes.

Improving the care of patients with advanced dementia will also require the evaluation of new regulatory and systems interventions that provide an incentive for the delivery of goaldirected care. Examples of such strategies include implementing quality metrics that are specific to this population, testing alternative payment structures tied to these metrics, and increasing resources to ensure access to high-quality palliative care across care settings.

\section{Guidelines}

The American Geriatrics Society, the Choosing Wisely campaign of the American Board of Internal Medicine Foundation, the American Academy of Hospice and Palliative Medicine, and the Alzheimer's Association have position statements about tube feeding in patients with advanced dementia. ${ }^{25-28}$ The Alzheimer's Association also has a position statement about end-of-life care. ${ }^{27}$ The recommendations in this review are consistent with these statements. 


\section{Conclusions and Recommendations}

The man in the vignette has advanced dementia and a presentation suggestive of aspiration pneumonia. With this presentation, the minimal clinical criteria for the initiation of antimicrobial agents for pneumonia in a nursing home patient are met (a temperature of $<38.8^{\circ} \mathrm{C}$, a new productive cough, and a respiratory rate of $>25$ breaths per minute) (see the Supplementary Appendix). ${ }^{36}$ Before the patient starts treatment, his daughter should be apprised of his status and should review the goals of care. If there are clear, comfort-focused goals, only treatments to relieve symptoms should be prescribed. Otherwise, the daughter should be counseled that her father's general prognosis is poor, regardless of treatment, owing to his underlying advanced dementia. She needs to understand that the aspiration pneumonia was precipitated by swallowing problems, which are common in patients with advanced dementia and will continue. Within that context, treatment options and their advantages and disadvantages should be outlined. If comfort measures are preferred, no further workup is indicated. Symptoms should be treated and hospice or palliative care should be offered. If the daughter feels that an attempt to extend her father's life aligns with his preferences, the administration of antimicrobials by the least invasive route should be initiated at the nursing home. If the daughter, after judicious counseling, thinks that her father would still want all potentially life-prolonging interventions (e.g., intubation), then that preference should be respected; antimicrobial treatment should be started at the nursing home, and the patient should be hospitalized if his condition deteriorates further. His goals of care should be revisited as his condition evolves.

\section{Supplementary Material}

Refer to Web version on PubMed Central for supplementary material.

\section{References}

1. Hebert LE, Weuve J, Scherr PA, Evans DA. Alzheimer disease in the United States (2010-2050) estimated using the 2010 census. Neurology. 2013; 80:1778-1783. [PubMed: 23390181]

2. Deaths: preliminary data for 2011. Natl Vital Stat Rep. 2011; 61(6):1-51.

3. Weuve J, Hebert LE, Scherr PA, Evans DA. Deaths in the United States among persons with Alzheimer's disease (2010-2050). Alzheimers Dement. 2014; 10(2):e40-e46. [PubMed: 24698031]

4. Todd S, Barr S, Roberts M, Passmore AP. Survival in dementia and predictors of mortality: a review. Int J Geriatr Psychiatry. 2013; 28:1109-1124. [PubMed: 23526458]

5. Arrighi HM, Neumann PJ, Lieberburg IM, Townsend RJ. Lethality of Alzheimer disease and its impact on nursing home placement. Alzheimer Dis Assoc Disord. 2010; 24:90-95. [PubMed: 19568155]

6. Mitchell SL, Teno JM, Miller SC, Mor V. A national study of the location of death for older persons with dementia. J Am Geriatr Soc. 2005; 53:299-305. [PubMed: 15673356]

7. Teno JM, Gozalo PL, Bynum JP, et al. Change in end-of-life care for Medicare beneficiaries: site of death, place of care, and health care transitions in 2000, 2005, and 2009. JAMA. 2013; 309:470477. [PubMed: 23385273]

8. Gill TM, Gahbauer EA, Han L, Allore HG. Trajectories of disability in the last year of life. N Engl J Med. 2010; 362:1173-1180. [PubMed: 20357280]

9. Reisberg B, Ferris SH, de Leon MJ, Crook T. The Global Deterioration Scale for assessment of primary degenerative dementia. Am J Psychiatry. 1982; 139:1136-1139. [PubMed: 7114305] 
10. Mitchell SL, Teno JM, Kiely DK, et al. The clinical course of advanced dementia. N Engl J Med. 2009; 361:1529-1538. [PubMed: 19828530]

11. Mitchell SL, Miller SC, Teno JM, Kiely DK, Davis RB, Shaffer ML. Prediction of 6-month survival of nursing home residents with advanced dementia using ADEPT vs hospice eligibility guidelines. JAMA. 2010; 304:1929-1935. [PubMed: 21045099]

12. Jayes RL, Arnold RM, Fromme EK. Does this dementia patient meet the prognosis eligibility requirements for hospice enrollment? J Pain Symptom Manage. 2012; 44:750-756. [PubMed: 23131703]

13. The National Hospice Organization. Medical guidelines for determining prognosis in selected noncancer diseases. Hosp J. 1996; 11:47-63. [PubMed: 8949013]

14. Buchanan A, Brock DW. Deciding for others. Milbank Q. 1986; 64(Suppl 2):17-94. [PubMed: 11649884]

15. Mitchell SL, Kiely DK, Lipsitz LA. The risk factors and impact on survival of feeding tube placement in nursing home residents with severe cognitive impairment. Arch Intern Med. 1997; 157:327-332. [PubMed: 9040301]

16. Teno JM, Gozalo PL, Mitchell SL, et al. Does feeding tube insertion and its timing improve survival? J Am Geriatr Soc. 2012; 60:1918-1921. [PubMed: 23002947]

17. Gozalo P, Teno JM, Mitchell SL, et al. End-of-life transitions among nursing home residents with cognitive issues. N Engl J Med. 2011; 365:1212-1221. [PubMed: 21991894]

18. Kiely DK, Givens JL, Shaffer ML, Teno JM, Mitchell SL. Hospice use and outcomes in nursing home residents with advanced dementia. J Am Geriatr Soc. 2010; 58:2284-2291. [PubMed: 21143437]

19. Givens JL, Kiely DK, Carey K, Mitchell SL. Healthcare proxies of nursing home residents with advanced dementia: decisions they confront and their satisfaction with decision-making. J Am Geriatr Soc. 2009; 57:1149-1155. [PubMed: 19486200]

20. Givens JL, Jones RN, Shaffer ML, Kiely DK, Mitchell SL. Survival and comfort after treatment of pneumonia in advanced dementia. Arch Intern Med. 2010; 170:1102-1107. [PubMed: 20625013]

21. Mitchell SL, Shaffer ML, Loeb MB, et al. Infection management and multidrug-resistant organisms in nursing home residents with advanced dementia. JAMA Intern Med. 2014; 174:1660-1667. [PubMed: 25133863]

22. Loeb M, Carusone SC, Goeree R, et al. Effect of a clinical pathway to reduce hospitalizations in nursing home residents with pneumonia: a randomized controlled trial. JAMA. 2006; 295:25032510. [PubMed: 16757722]

23. Sampson EL, Candy B, Jones L. Enteral tube feeding for older people with advanced dementia. Cochrane Database Syst Rev. 2009; 2:CD007209. [PubMed: 19370678]

24. Teno JM, Gozalo P, Mitchell SL, Kuo S, Fulton AT, Mor V. Feeding tubes and the prevention or healing of pressure ulcers. Arch Intern Med. 2012; 172:697-701. [PubMed: 22782196]

25. American Geriatrics Society Ethics Committee and Clinical Practice and Models of Care Committee. American Geriatrics Society feeding tubes in advanced dementia position statement. J Am Geriatr Soc. 2014; 62:1590-1593. [PubMed: 25039796]

26. Feeding tubes for people with Alzheimers disease. Philadelphia: ABIM Foundation; 2013. (http:// www.choosingwisely.org/doctor-patient-lists/feeding-tubes-for-people-with-alzheimers-disease).

27. Alzheimer's Association Statements. 2011 (http://www.alz.org/about_us_statements.asp).

28. Fischberg D, Bull J, Casarett D, et al. Five things physicians and patients should question in hospice and palliative medicine. J Pain Symptom Manage. 2013; 45:595-605. [PubMed: 23434175]

29. Hanson LC, Ersek M, Gilliam R, Carey TS. Oral feeding options for people with dementia: a systematic review. J Am Geriatr Soc. 2011; 59:463-472. [PubMed: 21391936]

30. Givens JL, Selby K, Goldfeld KS, Mitchell SL. Hospital transfers of nursing home residents with advanced dementia. J Am Geriatr Soc. 2012; 60:905-909. [PubMed: 22428661]

31. Hanson LC, Carey TS, Caprio AJ, et al. Improving decision-making for feeding options in advanced dementia: a randomized, controlled trial. J Am Geriatr Soc. 2011; 59:2009-2016. [PubMed: 22091750] 
32. D'Agata E, Loeb MB, Mitchell SL. Challenges in assessing nursing home residents with advanced dementia for suspected urinary tract infections. J Am Geriatr Soc. 2013; 61:62-66. [PubMed: 23311553]

33. D'Agata E, Mitchell SL. Patterns of antimicrobial use among nursing home residents with advanced dementia. Arch Intern Med. 2008; 168:357-362. [PubMed: 18299489]

34. Chen JH, Lamberg JL, Chen YC, et al. Occurrence and treatment of suspected pneumonia in longterm care residents dying with advanced dementia. J Am Geriatr Soc. 2006; 54:290-295. [PubMed: 16460381]

35. Morrison RS, Siu AL. Survival in end-stage dementia following acute illness. JAMA. 2000; 284:47-52. [PubMed: 10872012]

36. Loeb M, Bentley DW, Bradley S, et al. Development of minimum criteria for the initiation of antibiotics in residents of long-term-care facilities: results of a consensus conference. Infect Control Hosp Epidemiol. 2001; 22:120-124. [PubMed: 11232875]

37. Hendriks SA, Smalbrugge M, Hertogh CM, van der Steen JT. Dying with dementia: symptoms, treatment, and quality of life in the last week of life. J Pain Symptom Manage. 2014; 47:710-720. [PubMed: 23916680]

38. Volicer L, Hurley AC, Blasi ZV. Scales for evaluation of end-of-life care in dementia. Alzheimer Dis Assoc Disord. 2001; 15:194-200. [PubMed: 11723370]

39. Warden V, Hurley AC, Volicer L. Development and psychometric evaluation of the Pain Assessment in Advanced Dementia (PAINAD) scale. J Am Med Dir Assoc. 2003; 4:9-15. [PubMed: 12807591]

40. Sink KM, Holden KF, Yaffe K. Pharmacological treatment of neuropsychiatric symptoms of dementia: a review of the evidence. JAMA. 2005; 293:596-608. [PubMed: 15687315]

41. Schneider LS, Dagerman KS, Insel P. Risk of death with atypical antipsychotic drug treatment for dementia: meta-analysis of randomized placebo-controlled trials. JAMA. 2005; 294:1934-1943. [PubMed: 16234500]

42. Huskamp HA, Kaufmann C, Stevenson DG. The intersection of long-term care and end-of-life care. Med Care Res Rev. 2012; 69:3-44. [PubMed: 21903662]

43. Unroe KT, Meier DE. Quality of hospice care for individuals with dementia. J Am Geriatr Soc. 2013; 61:1212-1214. [PubMed: 23855849]

44. NHPCO's facts and figures: hospice care in America. Alexandria, VA: National Hospice and Palliative Care Organization; 2014. (http://www.nhpco.org/sites/default/files/public/ Statistics_Research/2014_Facts_Figures.pdf).

45. Miller SC, Lima JC, Looze J, Mitchell SL. Dying in U.S. nursing homes with advanced dementia: how does health care use differ for residents with, versus without, end-of-life Medicare skilled nursing facility care? J Palliat Med. 2012; 15:43-50. [PubMed: 22175816]

46. Miller SC, Gozalo P, Mor V. Hospice enrollment and hospitalization of dying nursing home patients. Am J Med. 2001; 111:38-44. [PubMed: 11448659]

47. Miller SC, Mor V, Wu N, Gozalo P, Lapane K. Does receipt of hospice care in nursing homes improve the management of pain at the end of life? J Am Geriatr Soc. 2002; 50:507-515. [PubMed: 11943048]

48. Shega JW, Hougham GW, Stocking CB, Cox-Hayley D, Sachs GA. Patients dying with dementia: experience at the end of life and impact of hospice care. J Pain Symptom Manage. 2008; 35:499_ 507. [PubMed: 18261878]

49. Holmes HM, Sachs GA, Shega JW, Hougham GW, Cox Hayley D, Dale W. Integrating palliative medicine into the care of persons with advanced dementia: identifying appropriate medication use. J Am Geriatr Soc. 2008; 56:1306-1311. [PubMed: 18482301]

50. Tjia J, Briesacher BA, Peterson D, Liu Q, Andrade SE, Mitchell SL. Use of medications of questionable benefit in advanced dementia. JAMA Intern Med. 2014; 174:1763-1771. [PubMed: 25201279] 


\section{Key Clinical Points}

\section{Advanced Dementia}

- Advanced dementia is a leading cause of death in the United States.

- Features include profound memory deficits (e.g., inability to recognize family), minimal verbal communication, loss of ambulatory abilities, the inability to perform activities of daily living, and urinary and fecal incontinence.

- The most common clinical complications are eating problems and infections, and these require management decisions.

- Advance care planning is a cornerstone of care. Treatment decisions should be guided by the goals of care; more than $90 \%$ of health care proxies state that patient comfort is the primary goal.

- Observational studies do not show any benefits of tube feeding in persons with advanced dementia, and tube feeding is not recommended.

- Observational studies show several benefits of hospice care. Patients with advanced dementia should be offered palliative and hospice care services if they are available. 


\section{Table 1}

\section{Hospice Guidelines for Estimating Survival of Less Than 6 Months in a Patient with Dementia.*}

Hospice guidelines for estimating survival of less than 6 months in a patient with dementia require that the patient meet the following two criteria regarding the Functional Assessment Staging (FAST) tool and medical conditions.

1 1. The patient must be at or beyond stage $7 \mathrm{c}$ on the FAST tool and have all the features of stages $6 \mathrm{a}$ through $7 \mathrm{c}$ :

Stage 1: Has no objective or subjective difficulties

Stage 2: Has subjective complaints of forgetting

Stage 3: Has decreased job functioning that is evident to coworkers and difficulty traveling to new locations

Stage 4: Has decreased ability to perform complex tasks (e.g., planning dinner for guests, handling finances)

Stage 5: Requires assistance in choosing proper clothes for the day, season, or occasion

Stage 6a: Cannot dress without assistance, occasionally or frequently

Stage 6b: Cannot bathe without assistance, occasionally or frequently

Stage 6c: Cannot perform mechanics of toileting without assistance, occasionally or frequently

Stage 6d: Is incontinent of urine, occasionally or frequently

Stage 6e: Is incontinent of bowel, occasionally or frequently

Stage 7a: Has speech limited to fewer than six intelligible words during an average day

Stage $7 \mathrm{~b}$ : Has speech limited to one intelligible word during an average day

Stage 7c: Is unable to ambulate independently

Stage 7d: Cannot sit up independently

Stage 7e: Cannot smile

Stage 7f: Cannot hold up head independently

2 2. The patient must have had at least one of the following medical conditions in the past year:

Aspiration pneumonia

Pyelonephritis or other upper urinary tract infection

Septicemia

Pressure ulcer, multiple, stage 3 or 4

Recurrent fever after treatment with antibiotics

Eating problems, defined as food or fluid intake that is insufficient to sustain life (i.e., in tube-fed patients, weight loss of $>10 \%$ during the previous 6 months or a serum albumin level of $<2.5 \mathrm{~g}$ per deciliter)

* Data are from the National Hospice Organization.13 
Table 2

Steps to Decision Making in Cases of Advanced Dementia.

\begin{tabular}{|c|c|c|}
\hline Step & Description & Application to the Vignette \\
\hline $\begin{array}{l}\text { 1. Clarify the } \\
\text { clinical } \\
\text { situation }\end{array}$ & $\begin{array}{l}\text { Educate health care proxy about advanced } \\
\text { dementia. Explain that it is a terminal illness } \\
\text { and describe its clinical course. } \\
\text { Explain the most likely clinical problems. }\end{array}$ & $\begin{array}{l}\text { Explain to the daughter that her father's prognosis is limited because of his } \\
\text { advanced dementia, which is a terminal illness; eating problems and } \\
\text { infections are expected complications. }{ }^{10,19} \text { His presumed aspiration } \\
\text { pneumonia is a consequence of swallowing problems, which are likely to be } \\
\text { ongoing. }\end{array}$ \\
\hline $\begin{array}{l}\text { 2. Establish } \\
\text { the preferred } \\
\text { level or goal } \\
\text { of care }\end{array}$ & $\begin{array}{l}\text { Base the decision about care on the perceived } \\
\text { preferences of the patient. Follow basic tenet } \\
\text { of surrogate decision making. }{ }^{14} \\
\text { Is the preference for only treatments that } \\
\text { promote comfort, for all available medical } \\
\text { interventions that may prolong life, or for a } \\
\text { "middle of the road" approach that includes } \\
\text { potentially curative but relatively conservative } \\
\text { treatments with the goal of the patient's return } \\
\text { to baseline status? }\end{array}$ & $\begin{array}{l}\text { Did the father previously express any wishes for his medical care? Are } \\
\text { there existing advance directives? On the basis of the father's values, what } \\
\text { does the daughter think he would want? What does she think is in his best } \\
\text { interest? }\end{array}$ \\
\hline $\begin{array}{l}\text { 3. Align } \\
\text { treatment } \\
\text { options with } \\
\text { preferred level } \\
\text { or goal of care }\end{array}$ & $\begin{array}{l}\text { Describe treatment options for specific } \\
\text { clinical problems. } \\
\text { Describe advantages and disadvantages of } \\
\text { options on the basis of the best available } \\
\text { evidence. Acknowledge limitations of data, } \\
\text { including lack of randomized, controlled } \\
\text { trials. } \\
\text { Once the proxy has been fully informed and } \\
\text { counseled, respect the proxy's choices. Be } \\
\text { sensitive to cultural background. Include } \\
\text { hospice referral and palliative care } \\
\text { consultation in the treatment plan when } \\
\text { appropriate. Revisit the goals of care as the } \\
\text { clinical status evolves. }\end{array}$ & $\begin{array}{l}\text { For pneumonia: If the daughter prefers comfort care for her father, treat } \\
\text { symptoms only (e.g., with antipyretics and oxygen). For the middle-of-the- } \\
\text { road approach, start antimicrobials at the nursing home, minimizing the } \\
\text { treatment burden as much as possible. Antimicrobials may prolong life for } \\
\text { several months, but their administration may cause discomfort }{ }^{20} \text { and can } \\
\text { have adverse effects, including acquisition of multidrug-resistant } \\
\text { organisms. }{ }^{21} \text { Hospitalize only if the daughter thinks that her father would } \\
\text { want all potentially life-prolonging treatments. Hospitalization may be } \\
\text { traumatic and unnecessary for the treatment of pneumonia }{ }^{20,22} \text { but provides } \\
\text { immediate access to life-sustaining interventions. } \\
\text { For eating problems (if acute infection resolves): If comfort care or the } \\
\text { middle-of-the-road approach is preferred, provide palliation and continue } \\
\text { hand feeding as long as it is comfortable for the patient. Hand feeding will } \\
\text { allow the father to taste food and be with caregivers at mealtimes, but his } \\
\text { intake will be limited. If the daughter thinks that her father would want all } \\
\text { interventions that may prolong his life, explain that observational studies } \\
\text { have shown that tube feeding does not extend survival; it has no } \\
\text { demonstrated benefits, is not associated with reduced aspiration, and has } \\
\text { risks. }{ }^{15,16,23,24} \text { Leading organizations recommend against tube feeding and } \\
\text { advocate hand feeding. }{ }^{25-28}\end{array}$ \\
\hline
\end{tabular}

